\title{
PROFESSIONAL EDUCATION
}

UDC 811.111:371.3(045)

Olena Petrashchuk, Prof.

\section{CONCEPT OF THE ENGLISH LANGUAGE TRAINING OF AIR NAVIGATION SERVICE PERSONNEL}

\author{
National Aviation University \\ E-mail: aamm@nau.edu.ua
}

\begin{abstract}
The article deals with the Concept of English language training of Air Navigation Service personnel, which is proposed for providing quality language training of the specialists. The proposed Concept is in tune with the up to date approach to vocational training (ICAO TRAINAIR PLUS) which prioritizes an employer's expectations then the standard educational programme.
\end{abstract}

Keywords: aeronautical radiotelephony, Air Navigation Service provider, ATC staff, communication, ICAO language requirements, professionally oriented English programme/training.

\section{Introduction}

The Concept was created first and foremost in order to elaborate the measures by which the English language proficiency levels of air traffic controllers could be brought in accordance with the levels stipulated by the International Civil Aviation Organization.

Pursuant to the decision ANC 150-13 of the Air Navigation Commission approved on 11 March 1999, the Proficiency Requirements in Common English Study Group (PRICE-SG) was established. A number of objectives were set for the group, which included the elaboration of the necessary amendments to Annex 1 - Aviation Staff Certification (Personnel Licensing) and Annex 10 Aeronautical Communication (Aeronautical Telecommunications) insofar as they touched upon the use of English in R/T. The aim of making these amendments was to motivate ICAO member-states to take the steps necessary for their pilots and controllers to attain the required English language proficiency levels. The PRICE Study Group also elaborated upon the minimum operational level of English language proficiency required by pilots and controllers.

On 5 March 2003, the ICAO Council approved the new Standards and Recommended Practices concerning the use of English while conducting aeronautical radiotelephony communication, as elaborated by the PRICE-SG. The new requirements are included in the following ICAO documents: Annex 1 - Personnel Licensing; Annex 6 Operation of Aircraft; Volume II of Annex 10 -
Aeronautical Telecommunications and Annex 11 Air Traffic Services.

EUROCONTROL requirements for English proficiency levels of technical staff.

At the present moment, ICAO Standards and Recommended Practices (SARPs) do not envisage special requirements for English proficiency levels of technical staff. The first regulatory document which highlighted such requirements was EUROCONTROL document ESARR5 (Eurocontrol Safety Regulatory requirements) approved on 11 April $2002[1 ; 2]$.

\section{Review of Research Results}

The objective of the Concept is:

the determination of:

- the training requirement;

- the training objective;

- the specialisation of training according to

three areas of professional activity;

the elaboration of:

- organizational criteria for training in both general and professionally oriented English;

- criteria for the assessment of English proficiency levels;

- recommendations concerning the introduction of requirements for English proficiency levels into job descriptions.

In order for the training programme to be accurately defined, there is a need for Air Navigation Service (ANS) providers to determine the English language training requirements of their personnel and to prepare information concerning these needs. 
The training objective will depend on the determined requirements concerning the use of English at workstations across a range of job descriptions:

- for controllers (civil and military) - the attainment of a level of language proficiency according to Level 4 (Operational) on the ICAO language proficiency rating scale;

- for technical personnel and other staff (including managerial, administrative, seconded military and other operational but non-ATC staff) the attainment of a level of language proficiency required by them in them in the effective performance of their professional duties.

The precise level of this professional English language competence and its means of assessment and grading are yet to be defined.

A further objective of the training programme must also be to allow the language trainees to subsequently maintain the levels of English language proficiency they have acquired.

With an understanding of the type of work and services conveyed by ANS providers, the Concept considers the English language training provision for ANS personnel according to the language demands in 3 main categories of professional activity:

1) controllers;

2) technicians;

3) general.

Each category has its own aims, methods, programmes and training terms.

1. Controllers: the language training of civil and assigned or seconded military controllers, instructors and operational controllers.

2. Technical specialists: the language training of technical specialists who deal with the operation and maintenance of air navigation systems.

3. General: the training of personnel not included in the two above-mentioned categories (for example: managerial, administrative, other operational but non-ATC staff and military staff operating in civil aviation).

The language training for those personnel falling within the Controllers' category is considered as the priority [2].

\section{Purpose of the work}

The organisation of general and professionally oriented English training is a key issue.

The language training of ANS personnel is to be offered or provided by the specialized educational programmes/courses [2;3].

\section{General and professionally oriented English}

Candidates for training whose English proficiency would require language training at a level generally recognized as being either Beginner or Elementary should be trained in general English notwithstanding their area of professional activity.

Specialists whose English proficiency is assessed as being at a level generally recognised as PreIntermediate or higher should be trained in English according to the professionally oriented English programme:

- the controllers' category including aviation English language training and phraseology for radiotelephony communication;

- the technical category including technical English;

- the general (managerial, administrative, etc.) including business English with professional language development in specific topics.

Requirements for lessons. Lessons should be organized in such a way that they could embrace all four types of language activities (reading, writing, listening and speaking) with a degree of flexibility leading to a certain bias according to the requirements of the specialists' professional activity. To reach this objective, lessons should be oriented towards the practical communicative use of English without an over-pre-occupation with the attainment of knowledge about the language [2;3].

Requirements for teachers. Teachers who perform the training in English should:

- hold a diploma of English teaching;

- have at least 3-years work experience in teaching adults;

- have a knowledge of ESP training techniques;

- have relevant teaching experience

- be aware of the requirements for English proficiency levels of specialists according to the ICAO criteria.

Curricula. The curricula for each category are developed on the basis of the specific requirements of the ANS providers to the staff as defined by the job language skills inventory (which may be different within different job places). A curriculum should be divided into modules. Each module should conclude in an end of module test.

Each curriculum should be based on the complex and integrated development of English language skills and abilities in the four key areas of language activities - reading, writing, listening and speaking. 
At the same time, corresponding to the areas of specialist professional activities outlined above, the curriculum requires particular attention being paid to:

- the development of skills and abilities of aural perception and speaking of ATC personnel;

- the development of skills in speaking, comprehension, writing and aural perception of technical information by technical personnel;

- the development of skills and abilities in speaking, aural perception, writing, reading and comprehension by personnel of general activity domain.

The level of English language skills and abilities attained is to be determined by means of specifically prepared tests. These tests will be employed in all pre-course, progress, end of course and qualification assessments. All assessment tests should reflect the specific language competencies required by the different categories of specialists in their areas of professional activity.

The selection of curriculum content (topics, situations, functions, structures, language and speech material) is to be made on the following principles:

- connections and consequences that allow all course components to be joined in a logical and consecutively formed matrix of exercises and assignments;

- professional orientation that will allow the training of specialists of different categories to be carried out according to the special requirements connected with use of English in their professional activity;

- modelling that will allow those activities to be modeled on language and speech training materials which can be used by specialists in their further professional activity.

\section{Principles in the teaching of new components/constituents in training courses}

General criteria:

- the methodology of the English language teaching should be oriented towards the professional activity of the specialists being trained;

- the mere acquirement of knowledge about the language is not considered a fundamental objective of the training programme.

\section{Listening:}

The development of listening skills is to be carried out on the basis of professionally directed authentic audio texts of different types.
Comprehension tests after listening should be as a rule presented in the following order: comprehension of general information, distinguishing specific information in audio text, listening in order to get detailed information and communicatively justified responses to information included in or derived from the text.

Speaking:

For the specialists of the controllers' category there is a requirement for a higher level of proficiency in the spoken language. As ANS specialists should effectively communicate in all possible situations of their professional duties they need corresponding practice in verbal communication. During training it is necessary to offer to trainees such exercises and assignments that will involve them in the use of English in conditions and activities that simulate as far as possible their professional communication tasks. For this purpose it is recommended to set tasks that will motivate specialists to communicate at lessons solely in English.

Reading:

Reading skills include the reading and comprehension of texts at both the general and detailed level. Activities and assignments directed at the development of reading skills could include such exercises as forecast assignments - providing the opportunity for trainees to infer text content on the basis of some definite information (e.g. heading); assignments requiring the trainees to extract particular information from implication; exercises that analyse the structure, style and genre of a text; exercises encouraging the trainees to use received information in further communication activities. Reading is often combined with other types of communicative activity (listening, speaking, writing and translation).

Writing:

The development of written communication skills is to be carried out by means of a combination of controlled writing activities and independent free writing assignments; moreover, both types of assignments presuppose the use of writing in the solving of different problems that may arise in the professional activity of ANS specialists. The training exercises should include assignments that develop writing proficiency of the trainees' and should be directed at enabling them to master skills in the planning, editing, and correction of a written text. 
In creative writing assignments, the intended audience for the text and the context in which it is written should be definitely determined in order for the trainees to be able to choose the correct corresponding functional style of writing.

In order to provide practice in written communication the trainees should be given the opportunity to write different professionally oriented texts determined as by the production activity.

\section{Grammar:}

Grammar material should be presented in the context of the training process with the aim of developing the trainees' grammar abilities while completing assignments that presuppose different professionally oriented situations and the revision of language material. Grammar exercises should differ in levels of complexity from controlled practice activities to those of a freer, more creative nature. The Controllers' category of training should pay special attention to the use of communicative language structures.

\section{Phonetics:}

In addition to the phonetic analysis of the language, the teaching of phonetics includes the development of aural and vocal skills as well as intonation abilities. Its primary aim should be to allow a specialist to communicate effectively in his/her professional duties. Exercises and assignments should adopt a communicative approach. Activities which have as their principal focus the phonetics of the language are best held in language laboratories.

\section{Vocabulary:}

Lexical units are presented and activated in all types of reproductive and receptive activities; they allow trainees to repeat and remember language material that they possess as well as to increase their active and passive vocabulary necessary for use in professional activity. The presentation of lexical material is connected with particular and defined texts and contexts through further revision of the material in different types of communicative activity; in this way constant activation of assimilated material is provided.

Grouping. Specialists should be grouped according to their English proficiency levels as determined by the results of introductory tests. It is the recommendation within this concept that the maximum number of trainees in any one group should be 12 .
Training Resources. Specialists' training should be carried out in adequately equipped rooms. It is the duty of care of the ANS providers to assure themselves of the suitability of the facilities and resources of any commercial language training institution with whom they enter into contract for the provision of a language training service.

The use of modern training technologies in English training. Specific computer programmes (CALL) Internet and other modern technologies could be used during lessons and for individual work as appropriate.

Training and probation abroad. The decision as to whether or not to send their personnel out-ofcountry for intensive language training is left to the discretion of the ANS providers.

\section{Assessment of English language proficiency levels}

Assessment of English language proficiency levels constitutes an integral part of the English language training of ANS staff. Proficiency assessment is an essential element in the determination of a specialists' ability to use English in their professional duties at the level sufficient for them to work effectively; Proficiency assessment is an area of particular concern for controllers for whom corresponding ICAO requirements exist [4].

Principles of assessment. Assessment is based on the following principles:

- the reliability and validity of the evaluation of the specialists' proficiency level in English with regard to the aims, activities and content of the training programmes;

- the communicative nature of the assessment: for the controllers' domain and for some categories of managerial and administrative staff the test must be an assessment that allows the level of acquired abilities principally in the spoken language to be determined;

- the variety of assessment techniques;

- the cohesion and increasing complexity of the tests for each training course.

Aims of assessment. The primary aim of the assessment process is to provide a means of evaluating the English language proficiency level of specialists before, during and after their formal language training [5]. 
Secondary aims of the assessment process may be to provide a means of:

1) evaluating the effectiveness of the training programmes and of different aspects of their implementation in the training process; and

2) providing information required for the continuing development of the language training process.

Assessment system. The system of assessment includes pre-course, progress, end of course and qualification testing. The aims and content of each of the different types of assessment should be compatible with the overall aims and content of the training programme.

Pre-course assessment presupposes the language testing of ANS staff in order to determine their starting level of English proficiency. The information gained from pre-course assessments should then be used to determine the composition and of the training groups and the level of the training programme onto which they are placed.

Progress assessments should be carried out in the course of the training programme. In the carrying out of progress assessments, assignments/tests should be taken from modules which are used during training.

End of course assessments are carried out at the end of each training course. In the carrying out of end of course assessments, special test assignments should be devised that allow assessors to determine the trainees level of mastery of the material presented to them during each particular training course. These test exercises should have a similar structure to the activities devised for the qualification English tests to come and provide the specialists with the possibility of preparation for their qualification tests.

Qualification tests in English are to be carried out to determine the professional English language proficiency levels of the personnel of the ANS providers.

Qualification assessment tests should meet the main qualitative characteristics of English tests; in particular they should be valid, reliable and practical. Provided the requirements for test preparation, test procedures, and the qualified evaluation of test results are met, the qualification assessment will allow reliable and objective indicators of the English language proficiency levels of ANS personnel to be obtained.

Qualification assessment should be carried out only after the completion of the whole of the training programme.

Introductory, progress and final assessments should be carried out within the training course.

\section{Conclusions}

The realization of the Concept will provide for an increase in the English language proficiency of ANS staff, which in turn will allow the ANS providers:

- to meet ICAO requirements for ATC English language proficiency levels, so meeting ESARR5 requirements concerning English proficiency level of technical staff;

- to increase the quality of air traffic services and the level of flight safety.

\section{References}

1. Chicago Convention Appendix to Annex 1, Personnel Licensing.

2. Manual on the Implementation of ICAO Language Proficiency Requirements. - ICAO Doc 9835 AN/453: ICAO Second Edition, 2010. 186 p.

3. Douglas, D. Language for Specific Purposes Assessment Criteria: where do they come from? Language Testing. April: Int. Lang.Testing Ass. 2001. Vol. 18. N 2: 171-185.

4. Language Testing Criteria for Global Harmonization. - ICAO Cir 318 AN/180. - ICAO, 2009. $-38 \mathrm{p}$.

5. Mell, J. Standards for selection and development of language tests. - ICAO-Special Workshop on Language Proficiency, Baku, Azerbaijan, 7th-9th December 2005. 